Article

\title{
Extended State Observer-Based Predictive Speed Control for Permanent Magnet Linear Synchronous Motor
}

\author{
Yao Wang $\mathbb{D}^{\mathbb{D}}$, Haitao Yu * Zhiyuan Che ${ }^{\mathbb{D}}$, Yuchen Wang and Cheng Zeng \\ School of Electrical Engineering, Southeast University, Nanjing 210096, China \\ * Correspondence: htyu@seu.edu.cn
}

Received: 19 August 2019; Accepted: 6 September 2019; Published: 11 September 2019

check for updates

\begin{abstract}
Combining the feedback of predictive function control and the feedforward of extended state observer, a composite control strategy is proposed for the permanent magnet linear synchronous motor (PMLSM). The mathematical model of the PMLSM vector control system is established based on the basic structure and operation mechanism of PMLSM. Then, a speed regulator based on predictive function control ( $\mathrm{PFC}$ ) is designed to improve the speed tracking performance of the PMLSM drive system. The state and disturbance of the PMLSM system estimated by the extended state observer (ESO) transferred to the PMLSM drive system, and the robustness of the drive system will be improved. Comparative simulation and experiment results show that the proposed method has better speed tracking performance and disturbance rejection property.
\end{abstract}

Keywords: permanent magnet linear synchronous motor (PMLSM); extended state observer (ESO); predictive function control (PFC); composite control; robustness

\section{Introduction}

Permanent magnet linear synchronous motors (PMLSMs) have been widely used in industrial applications due to the high speed, high acceleration, high accuracy, and high-power density [1]. However, the PMLSM is a nonlinear system characterized by time-varying, strong coupling, and external disturbances [2], thus the control of the PMLSM servo system is still challenging. For the sake of meeting the requirements of system static and dynamic performances performances, it is necessary to study novel control strategies and improve the robustness of the vector control system [3].

A considerable number of research literatures have been reported in the motor control community [3-10]. Generally, there are two aspects that can be considered to achieve a good dynamic performance for a PMLSM. One type of efficient method is to optimize the structure design of the PMLSM, for example, an optimal design of the auxiliary-teeth model was carried out to decrease the circulating current of PMLSM, and the effect of the unbalanced phase based on the auxiliary-teeth installation was considered [4]. However, for the PMLSM herein, another method is to design an appropriate control strategy to improve the robustness of PMLSM, which is of great significance. For the wafer stage of the lithography systems, Song et al. [3] presented an iterative learning control (ILC)-based feedforward compensation scheme. In the presence of parameter uncertainties and external disturbances, a reduced-order proportional-integral (PI)-based robust cascade control was presented to enhance the robust performance of current and speed regulations [5]. The sliding mode control (SMC) has been extensively investigated for a few decades because of its particular robustness to suppress the disturbances [6], and an extended state observer (ESO)-based SMC control for the permanent magnet synchronous motor (PMSM) servo system was presented in the work by the authors of [7]. In the framework of the active disturbance rejection control (ADRC) technique [8], Sira-Ramirez et al. [9] designed an active disturbance rejection control scheme for the angular velocity trajectory tracking. In the work by the authors of [10], a comprehensive overview on disturbance/uncertainty estimation 
and attenuation techniques in PMSMs were given, where the various disturbances and uncertainties were discussed, and the relevant control methods were summarized.

In recent years, the model predictive control (MPC) technology has been well developed due to its conceptual simplicity, high dynamic response, and easy implementation etc. [11]. As mentioned in the work by the authors of [12], the MPC is one of the most popular control strategy in industrial applications, where satisfactory system performances can be guaranteed. One can regard the MPC as an optimal control method [13], which predicts the output of the state variable by employing the dynamic model of the controlled plant [14] and generates the future control input according to the optimization of the performance index function or cost function during each sampling period [15]. In the work by the authors of [16], three predictive current control schemes were compared by theoretical analyses, simulation results, and experiments. By replacing the conventional cascade structure, the speed and current controllers were combined together, and the MPC algorithm was applied to electrical drives [17]. Zhang et al. [18] presented a composite observer-based robust fault-tolerant predictive current control algorithm for PMSMs, which can eliminate the influence of motor parameter perturbation and permanent magnet demagnetization. Based on the field-oriented control (FOC) and vector control approaches, Liu et al. [19] proposed a composite speed regulation comprised by ESO feedforward compensation and predictive functional control (PFC) feedback control. In addition, an ESO can timely estimate the "lumped disturbances", including both internal unmodelled dynamics and external disturbances in the system [20], and thus the ESO-based control approaches (usually called ADRC schemes) can handle large uncertainties as well as achieve the desired performance [21]. It should be emphasized that most of the existing results are concentrated on PMSM servo control. However, the PMLSM is widely used in many applications. Thus, the investigation about designing an ESO-based MPC/PFC law to compensate the adverse effects of uncertainties and disturbances on a PMLSM is of significant importance, which remains as an open area.

The rest of this paper is organized as follows. In Section 2, the mathematical description of a PMLSM is analyzed and its simplified model is established. The main results are given in Section 3. The PFC controller is designed, and an ESO feedforward compensation is incorporated in the PFC feedback item, thus a composite speed regulate scheme is developed. Simulation results and comparative experiments are given to confirm the advantages and disturbance rejection performance of the proposed method in Section 4. Section 5 concludes the paper.

\section{Mathematical Model of the Pmlsm}

The objective of the servo system is tracking the reference signals as closely as possible, while guaranteeing control system and anti-disturbance performances. In this section, the mathematical model of the PMLSM is established in Laplace domain.

\subsection{Mathematical Description of a Pmlsm}

Generally, the basic equations of the PMLSM servo control system include the voltage equation, flux linkage equation, electromagnetic force equation, and the mechanical motion equation [22]. With the assumptions that the three-phase primary windings of the PMLSM are completely symmetrical and the traveling wave magnetic field is sinusoidally distributed [23], one can describe the PMLSM on the two-phase orthogonal synchronous rotating coordinate (d-q) as follows,

$$
\left\{\begin{array}{l}
L_{\mathrm{d}} \frac{d i_{\mathrm{d}}}{d t}=u_{\mathrm{d}}-R i_{\mathrm{d}}+\frac{\pi}{\tau} v \psi_{\mathrm{q}} \\
L_{\mathrm{q}} \frac{d i_{\mathrm{q}}}{d t}=u_{\mathrm{q}}-R i_{\mathrm{q}}-\frac{\pi}{\tau} v \psi_{\mathrm{d}} \\
F_{\mathrm{e}}=\frac{3 \pi}{2 \tau}\left[\psi_{\mathrm{f}} i_{\mathrm{q}}+\left(L_{\mathrm{d}}-L_{\mathrm{q}}\right) i_{\mathrm{d}} i_{\mathrm{q}}\right] \\
M \frac{d v}{d t}=F_{\mathrm{e}}-F_{L}-B_{\mathrm{f}} v
\end{array}\right.
$$


where $i_{\mathrm{d}}, u_{\mathrm{d}}, L_{\mathrm{d}}, \psi_{\mathrm{d}}, i_{\mathrm{q}}, u_{\mathrm{q}}, L_{\mathrm{q}}$, and $\psi_{\mathrm{q}}$ are the $d$-axis and $q$-axis currents, voltages, inductances, and flux linkages, respectively; $\psi_{\mathrm{f}}$ is the permanent magnet flux linkage; $R$ is the winding resistance; $\tau$ is the pole pitch; $F_{\mathrm{e}}$ is the electromagnetic force; $F_{\mathrm{L}}$ is the load torque; $B_{\mathrm{f}}$ is the viscous friction coefficient; $v$ and $M$ are the velocity and the mass of linear motor rotor, respectively.

Considering a surface-mounted PMLSM, and thus $L_{\mathrm{d}}=L_{\mathrm{q}}=L$. We can assume that there no hysteresis, no eddy currents, no cogging, no bearing components, no magnetic saturation, no temperature rise leading to a higher resistance $R$ and lower magnet flux, perfect magnetic alignment with an ideal symmetric 3-phase motor amplifier are exhibited [24]. In addition, we define the force constant as $K_{\mathrm{f}}=3 \pi / 2 \tau \cdot \psi_{\mathrm{f}}$. As a result, the Equation (1) can be rewritten as

$$
\left\{\begin{array}{l}
u_{\mathrm{d}}=L \frac{d i_{\mathrm{d}}}{d t}+R i_{\mathrm{d}}-\frac{\pi}{\tau} v L i_{\mathrm{q}} \\
u_{\mathrm{q}}=L \frac{d d_{\mathrm{q}}}{d t}+R i_{\mathrm{q}}+\frac{\pi}{\tau} v\left(L i_{\mathrm{d}}+\psi_{\mathrm{f}}\right) \\
M \frac{d v}{d t}=K_{\mathrm{f}} i_{q}-F_{L}-B_{\mathrm{f}} v
\end{array}\right.
$$

where $\psi_{\mathrm{q}}=L i_{\mathrm{q}}$ and $\psi_{\mathrm{d}}=L i_{\mathrm{d}}+\psi_{\mathrm{f}}$, respectively.

\subsection{A Simplified Model of the Pmlsm}

By the framework of FOC and vector control technique [25], a cascade structure comprising the speed regulation and current controllers is usually adopted in the PMLSM servo system [26]. Because the excitation flux linkage is established by permanent magnets, the current $i_{\mathrm{d}}$ is controlled to be zero in the inner loop, while the electromagnetic force is proportional to the current $i_{\mathrm{q}}$, whose command current is determined by the outer speed loop. It should be emphasized that the dynamics of current loop is usually much faster than speed loop response, that is, the current loop has a higher bandwidth that of speed loop. As a result, the current $i_{\mathrm{q}}$ nearly equals to its expected value $i_{\mathrm{q}}^{*}$ and thus the transfer function of inner current loop can be regarded as 1, i.e., $G_{i}(s) \approx 1$ [27]. To this end, the simplified control diagram of the PMLSM servo system is shown in Figure 1. In Figure 1, e denotes the velocity tracking error satisfying $e=v^{*}-v$, and $v^{*}$ is the given signal.

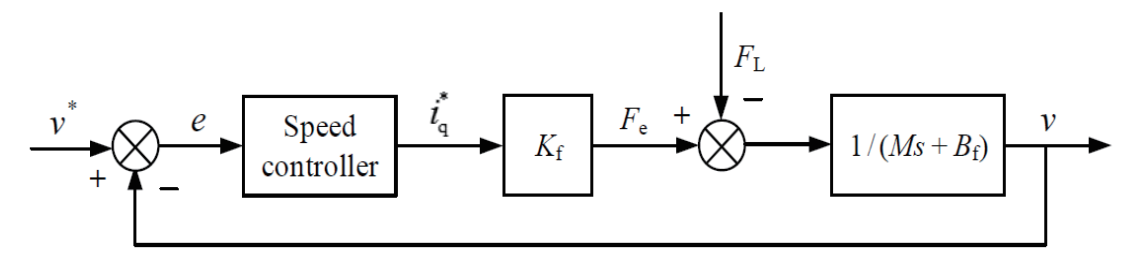

Figure 1. The simplified control diagram of the PMLSM servo system.

According to the control scheme of PMLSM given in Figure 1, the first-order system model in the Laplace domain can be expressed as

$$
\Omega(s)=\frac{K_{\mathrm{f}} I_{\mathrm{q}}^{*}(s)-F_{\mathrm{L}}(s)}{M s+B_{\mathrm{f}}}
$$

\section{ESO-Based PFC Design}

In this section, a PFC law is firstly designed based on the mathematical model obtained in Section 2. Then, an ESO is constructed to estimate the disturbances in the PMLSM servo system, which are incorporated in the PFC feedback controller. Finally, the whole block diagram for the PMLSM control system is derived. 


\subsection{PFC Design}

Among all the MPC approaches, PFC is characterized by the low online computation, while maintaining the advantages of the MPC method. In general, the PFC design methodology mainly comprises the following five components.

- (1) Basic functions

$$
i_{\mathrm{q}}^{*}(k+i)=\sum_{j=1}^{N} \mu_{j} u_{b j}(i), \quad i=1,2, \ldots, P
$$

where $i_{\mathrm{q}}^{*}$ is the future control variables, $N$ is the number of base functions, $\mu_{j}$ is the coefficients related to the performance optimization index, $u_{b j}(i)$ is the base functions determined by the reference signals, and $P$ is the optimization horizon.

In this paper, we select the base function as the form of step response, i.e., $u_{b j}(i)=1$, and set $N=1$. As a result, the following equation can be derived.

$$
i_{\mathrm{q}}^{*}(k)=\mu_{1}
$$

- (2) Prediction model

The prediction model of the plant output can be given in its discrete time form, the following formulation is easily obtained by applying the Euler discretization method to Equation (3).

$$
v_{\mathrm{m}}(k+1 \mid k)=\alpha_{\mathrm{m}} v_{\mathrm{m}}(k)+K_{\mathrm{m}}\left(1-\alpha_{\mathrm{m}}\right) i_{\mathrm{q}}^{*}(k)
$$

where $v_{\mathrm{m}}(k+1 \mid k)$ is the predicted velocity at time $t=(k+1) T_{\mathrm{s}}$ and $T_{\mathrm{s}}$ is the sample time; $K_{\mathrm{m}}$ and $\alpha_{\mathrm{m}}$ are coefficients of the prediction model (differential equation form).

For the $(k+2)$ th sampling time, we have

$$
v_{\mathrm{m}}(k+2 \mid k)=\alpha_{\mathrm{m}} v_{\mathrm{m}}(k+1)+K_{\mathrm{m}}\left(1-\alpha_{\mathrm{m}}\right) i_{\mathrm{q}}^{*}(k+1)
$$

According to the well-known mean-level control strategy [28], the control variables are regarded as a constant during the prediction, that is,

$$
i_{\mathrm{q}}^{*}(k)=i_{\mathrm{q}}^{*}(k+1)=\cdots=i_{\mathrm{q}}^{*}(k+P-1)
$$

By replacing $v_{\mathrm{m}}(k+1 \mid k)$ with $v_{\mathrm{m}}(k+1)$ and combining Equations (6)-(8) we get

$$
v_{\mathrm{m}}(k+2 \mid k)=\alpha_{\mathrm{m}}^{2} v_{\mathrm{m}}(k)+K_{\mathrm{m}}\left(1-\alpha_{\mathrm{m}}^{2}\right) i_{\mathrm{q}}^{*}(k)
$$

Obeying the same principle, the prediction output generated at the $(k+2)$ th sampling time is as follows,

$$
v_{\mathrm{m}}(k+i \mid k)=\alpha_{\mathrm{m}}^{i} v_{\mathrm{m}}(k)+K_{\mathrm{m}}\left(1-\alpha_{\mathrm{m}}^{i}\right) i_{\mathrm{q}}^{*}(k)
$$

Correspondingly, we can described the prediction output as the matrix form based on the Equations (5), (6), (9), and (10), which is as follows,

$$
V_{\mathrm{m}}(k)=V_{\mathrm{o}}(k)+V_{\mathrm{b}}(k) \mu_{1}
$$

where

$$
\begin{aligned}
V_{\mathrm{m}}(k) & =\left[\begin{array}{llll}
v_{\mathrm{m}}(k+1 \mid k) & v_{\mathrm{m}}(k+2 \mid k) & \cdots & v_{\mathrm{m}}(k+P \mid k)
\end{array}\right]^{\mathrm{T}} \\
V_{\mathrm{o}}(k) & =\left[\begin{array}{llll}
\alpha_{\mathrm{m}} & \alpha_{2}^{P} & \cdots & \alpha_{\mathrm{m}}^{P}
\end{array}\right]^{\mathrm{T}} v_{\mathrm{m}}(k) \\
V_{\mathrm{b}}(k) & =K_{m}\left[\begin{array}{llll}
\left(1-\alpha_{\mathrm{m}}\right) & \left(1-\alpha_{2}^{P}\right) & \cdots & \left(1-\alpha_{\mathrm{m}}^{P}\right)
\end{array}\right]^{\mathrm{T}}
\end{aligned}
$$


- (3) Error correction

Because the presence of the model mismatch, unknown disturbance, parameter variation, and noise, the prediction error between prediction model output and actual output is existed. When PFC is applied to control systems with a small sampling period, it is generally believed that the error in this processing period remains constant [19]. Since the sampling period of the PMLSM control system in this paper is $10^{-4} \mathrm{~s}$, it is assumed that all prediction errors are equal only within this interruption period. The error can be expressed as follows,

$$
e(k)=e(k+1)=e(k+2)=\cdots=e(k+P-1)=v(k)-v_{\mathrm{m}}(k)
$$

where $v(k)$ is the measured velocity of the practical control system.

- (4) Reference trajectory

A first-order reference trajectory is provided in the following form.

$$
v_{\mathrm{r}}(k+i)=v^{*}(k+i)-\alpha_{\mathrm{r}}^{i}\left[v^{*}(k)-v(k)\right] \quad i=1,2, \ldots, P
$$

where $v_{\mathrm{r}}$ is the velocity reference trajectory, $v^{*}$ is the set point value, $\alpha_{\mathrm{r}}=e^{-T_{\mathrm{S}} / T_{\mathrm{r}}}$ is the time constant, and $T_{\mathrm{r}}$ is the desired response time.

- (5) Evaluation mechanism

Considering the tracking error between the velocity reference trajectory $v_{\mathrm{r}}$ and the predicted output $v_{\mathrm{m}}$, and minimizing the sum of squared error $e$ with a penalization on the control input $i_{\mathrm{q}^{\prime}}^{*}$ yield the following quadratic performance index.

$$
\min J=\sum_{i=1}^{P} q_{i}^{2}\left[v_{\mathrm{r}}(k+i)-v_{\mathrm{m}}(k+i \mid k)-e(k+i)\right]^{2}+r^{2} i_{\mathrm{q}}^{* 2}(k)
$$

where $q_{i}$ are the parameters imposed on each of the tracking errors and $e ; r$ is a weighting parameter of the control input.

Define the following matrices.

$$
\begin{aligned}
& V_{\mathrm{r}}(k)=\left[\begin{array}{llll}
v_{\mathrm{r}}(k+1) & v_{\mathrm{r}}(k+2) & \cdots & v_{\mathrm{r}}(k+P)
\end{array}\right]^{\mathrm{T}} \\
& E(k)=\left[\begin{array}{llll}
e(k+1) & e(k+2) & \cdots & e(k+P)
\end{array}\right]^{\mathrm{T}} \\
& Q=\left[\begin{array}{cccc}
q_{1}^{2} & 0 & \cdots & 0 \\
0 & q_{i}^{2} & \cdots & 0 \\
\vdots & \vdots & \ddots & \vdots \\
0 & 0 & \cdots & q_{i}^{2}
\end{array}\right]^{\mathrm{T}}, \quad R=r^{2}
\end{aligned}
$$

Substituting Equations (12) and (16) into (15) leads to the following cost function.

$$
J=Q\left\|V_{\mathrm{r}}(k)-V_{\mathrm{m}}(k)-E(k)\right\|^{2}+R i_{q}^{* 2}(k)
$$

where $\|\cdot\|$ denotes the Euclidean norm.

According to the optimization theory [29], we can obtained the following controller by calculating $\partial J / \partial i_{\mathrm{q}}^{* 2}=0$.

$$
i_{\mathrm{q}}^{*}=\left(V_{\mathrm{b}}^{\mathrm{T}} Q V_{\mathrm{b}}+R\right)^{-1} V_{\mathrm{b}}^{\mathrm{T}} Q\left[V_{\mathrm{r}}(k)-V_{\mathrm{o}}(k)-E(k)\right]
$$

In a summary, the PFC law is derived as Equation (18). 


\subsection{ESO Design}

As mentioned in the work by the authors of [30], the observer-based feedforward compensation method can improve the disturbance rejection performance. In this note, we introduce an ESO to estimate the disturbances, whose estimates will be taken the above designed PFC into account.

Extracting the mechanical motion equation from Equation (2), and rewriting it as the following differential equation form.

$$
\dot{v}=\frac{K_{\mathrm{f}}}{M} i_{\mathrm{q}}-\frac{F_{L}}{M}-\frac{B_{\mathrm{f}}}{M} v=\frac{K_{\mathrm{f}}}{M} i_{\mathrm{q}}^{*}+d(t)
$$

where the lumped disturbance $d(t)$ (containing tracking error of q-axis current loop, external load torque and friction) is as follows:

$$
d(t)=\frac{K_{\mathrm{f}}}{M}\left(i_{\mathrm{q}}-i_{\mathrm{q}}^{*}\right)-\frac{F_{L}}{M}-\frac{B_{\mathrm{f}}}{M} v
$$

whose derivative is assumed to be bounded, namely, satisfying $\dot{d}(t) \leq D$.

The function $d(t)$ is generally unknown and the ESO can generate the disturbance estimate only depending on the input and output information of the control plant [20], which is free of the specific mathematical models. Here, we define the following state variables.

$$
\left\{\begin{array}{l}
x_{1}=v \\
x_{2}=d(t)
\end{array}\right.
$$

Substituting Equation (21) into (19) yields

$$
\left\{\begin{array}{l}
\dot{x}_{1}=x_{2}+b i_{q}^{*} \\
\dot{x}_{2}=D
\end{array}\right.
$$

where $b$ is a coefficient determined by the system parameters, i.e., $b=K_{\mathrm{f}} / M$.

In this paper, we construct the ESO as follows,

$$
\left\{\begin{array}{l}
\varepsilon=z_{1}-x_{1} \\
\dot{z}_{1}=z_{2}-c_{1} \varepsilon+b_{o} i_{q}^{*} \\
\dot{z}_{2}=-c_{2} \varepsilon
\end{array}\right.
$$

where $z_{1}$ and $z_{2}$ are the estimates of the state variables $x_{1}$ and $x_{2} ; c_{1}$ and $c_{2}$ are the gains of designed ESO to be determined; $b_{o}$ is the estimate of parameter $b$.

Based on the stability analysis in the work by the authors of [8], if the gains $c_{1}$ and $c_{2}$ are appropriately selected, the estimate errors between $z_{1}, z_{2}$ and $x_{1}, x_{2}$ can be guaranteed to be zero, that is,

$$
\left\{\begin{array}{l}
z_{1} \rightarrow x_{1} \rightarrow v \\
z_{2} \rightarrow x_{2} \rightarrow d(t)
\end{array}\right.
$$

After the total disturbance $f(t)$ is accurately estimated by the above ESO, one can be incorporated in aforementioned Equation (18) as a feedforward compensation to improve the anti-disturbance performance [31], and thus the composite speed regulator can be obtained as follows.

$$
i_{\mathrm{q}}^{*}=\left(V_{\mathrm{b}}^{\mathrm{T}} Q V_{\mathrm{b}}+R\right)^{-1} V_{\mathrm{b}}^{\mathrm{T}} Q\left[V_{\mathrm{r}}(k)-V_{\mathrm{o}}(k)-E(k)\right]-z_{2} / b_{0}
$$

As a result, the whole block diagram of the proposed composite control for the PMLSM servo system is given in Figure 2. 


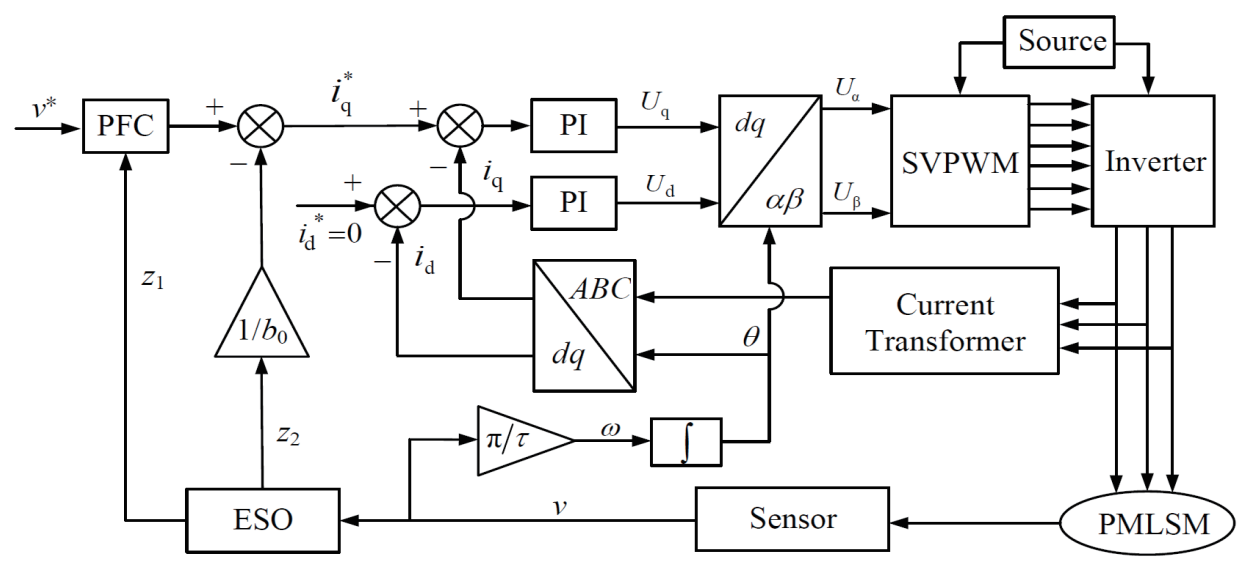

Figure 2. The ESO-based PFC control for the PMLSM.

\section{Simulation and Experimental Results}

In this section, some simulation results and comparative experiments will be conducted to demonstrate the effectiveness and advantages of the proposed ESO-based PFC composite control strategy. The parameters of the PMLSM are exhibited in Table 1.

Table 1. Parameters of the permanent magnet linear synchronous motor (PMLSM).

\begin{tabular}{ccc}
\hline Parameter & Value & Unit \\
\hline Rated voltage $(U)$ & 24 & $\mathrm{~V}$ \\
Pole pitch $(\tau)$ & 32 & $\mathrm{~mm}$ \\
Winding resistance $(R)$ & 1.25 & $\Omega$ \\
Inductance $(L)$ & 5.25 & $\mathrm{mH}$ \\
Viscous friction coefficient $\left(B_{\mathrm{f}}\right)$ & 2.12 & $\mathrm{~N} \cdot \mathrm{m} / \mathrm{s}$ \\
Flux linkage $\left(\psi_{\mathrm{f}}\right)$ & 0.0385 & $\mathrm{~Wb}$ \\
Mass $(M)$ & 14 & $\mathrm{~kg}$ \\
\hline
\end{tabular}

\subsection{Simulation Study}

In order to illustrate the advantages of the proposed composite control scheme over the conventional PID control method, the simulation comparisons are performed in this subsection. The simulation results are shown in Figures 3 and 4.

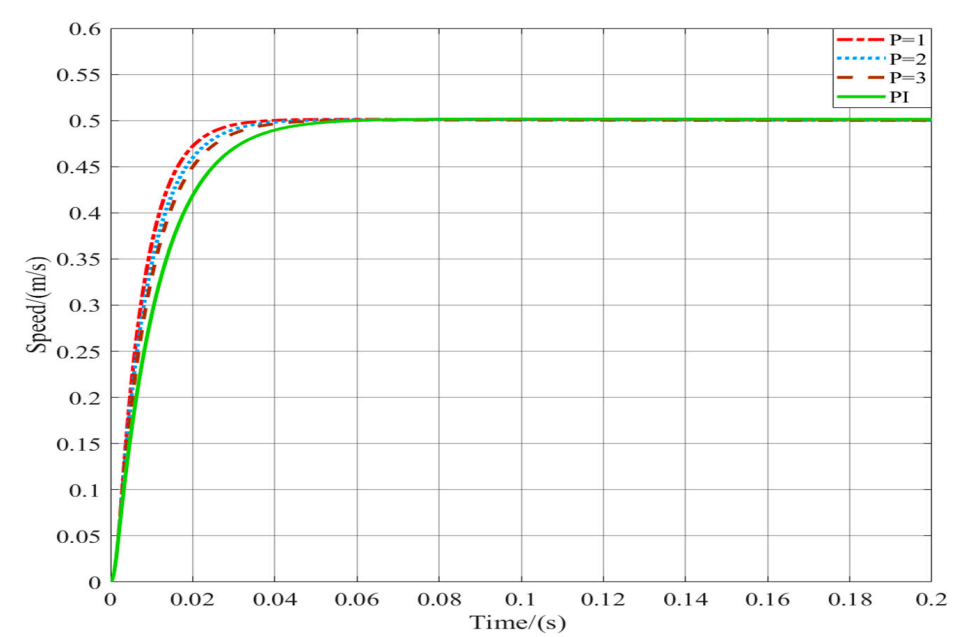

Figure 3. Speed tracking for proportional-integral (PI) and composite controllers (without load torque). 
For the case of no external load torque, Figure 3 shows the velocity evolutions based on PI controller and that of ESO-based PFC controller. According to the simulation results, the speed response of PFC controller is significantly faster than that of traditional PI controller, which reflects the superiority of the predictive control algorithm. In PFC controller, the value of prediction depth (also called optimization horizon) $P$ can be arbitrarily set. The simulation curves show that when the optimal prediction depth is set as $P=1$, the response speed is the fastest, and with the $P$ increasing, the response speed will slow down. Figure 4 shows the system performance of the PI and PFC + ESO when an external disturbances is suddenly loaded. It can be concluded that PFC + ESO control scheme has superior anti-disturbance performance.

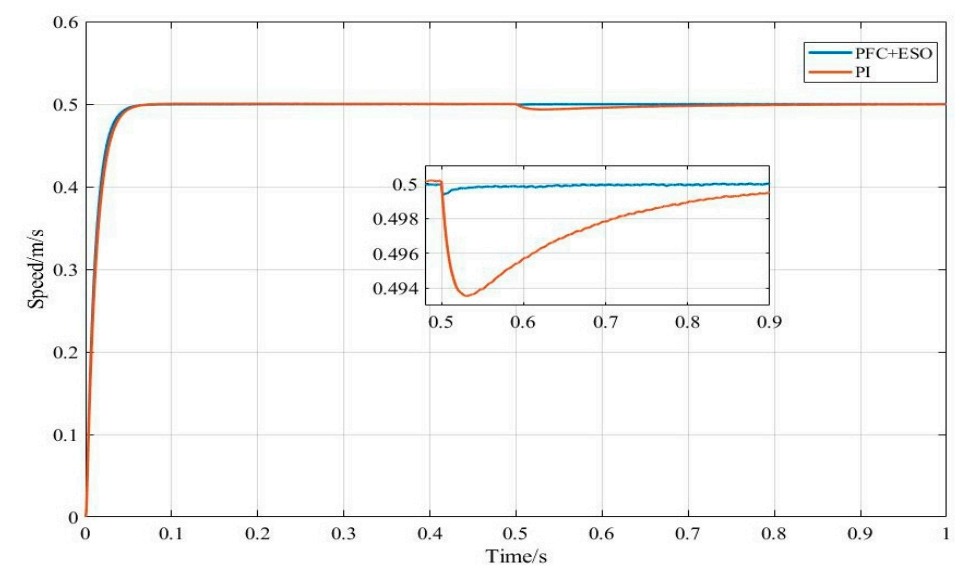

Figure 4. Performance comparison between PI and predictive function control (PFC) + extended state observer (ESO).

\subsection{Experiment Comparisons}

To evaluate the performance of the proposed method, the experimental setup for a PMLSM test system has been developed, which is shown in Figure 5. The overall speed regulate algorithm including the space vector pulse width modulation (SVPWM) implemented on the STM32 control board, intelligent power module (IPM) integrated driven circuit, external AD7606 conversion circuit, current and position sampling circuits (Hall-effect devices), oscilloscope, computer, Emulator, PMLSM, DC $15 \mathrm{~V}$ and DC $24 \mathrm{~V}$ power source, etc.

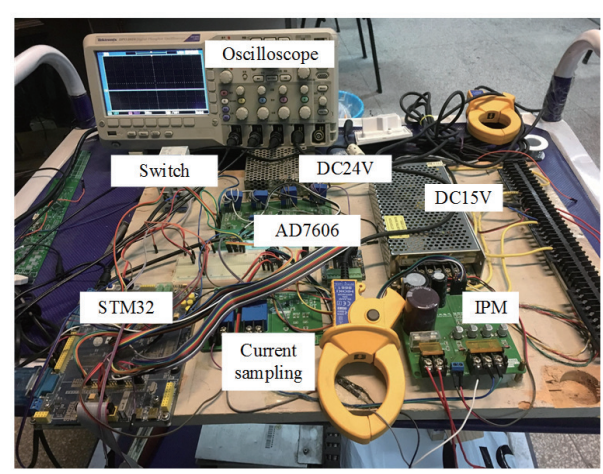

(a) Configuration of the test system

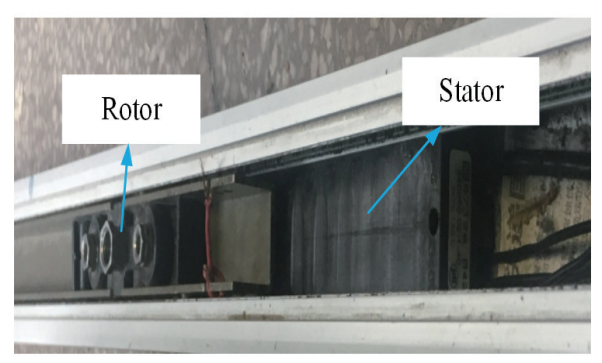

(b) Permanent magnet synchronous linear motor

Figure 5. Experiment setup. 
In order to verify the advantages and effectiveness of the composite control scheme, comparative simulations and experiments are established on optimized PID controller and the proposed method, respectively; with no speed overshoot as the constraint and the parameters tracking the reference speed in the shortest time are taken as the optimal parameters of the PID. The parameters of the proposed method are determined by the same method.

\subsubsection{No-Load Experiments}

Experiment results based on PI controller and ESO-based PFC controller (the predicted depth is set as $P=1$ ) are performed without external load torque, which are shown in Figure 6. In Figure 6, the reference speed is given as $v_{\text {ref }}=0.5 \mathrm{~m} / \mathrm{s}$, it can be seen from the experiment results that the speed response of PFC controller is faster than that of PI controller, and the system has superior performance.

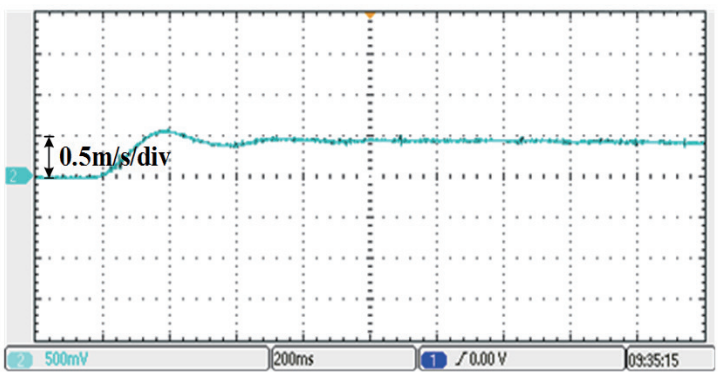

(a) PI control

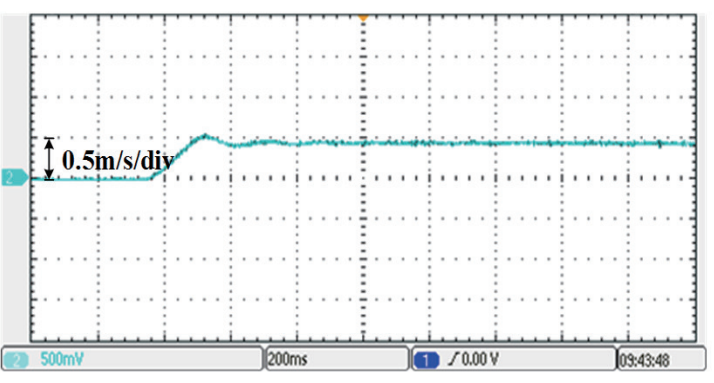

(b) ESO-based PFC control

Figure 6. Speed response curves (no load).

\subsubsection{Load Torque Experiments}

During the stable operation of the PMLSM, a load disturbance is suddenly loaded in a step form, the speed response curves based on PI and PFC + ESO controllers are shown in Figure 7. By comparing the results, it can be concluded that the proposed control scheme has faster response speed, and stronger robustness to external disturbance. In addition, the proposed ESO algorithm can well estimate the system state and disturbance.

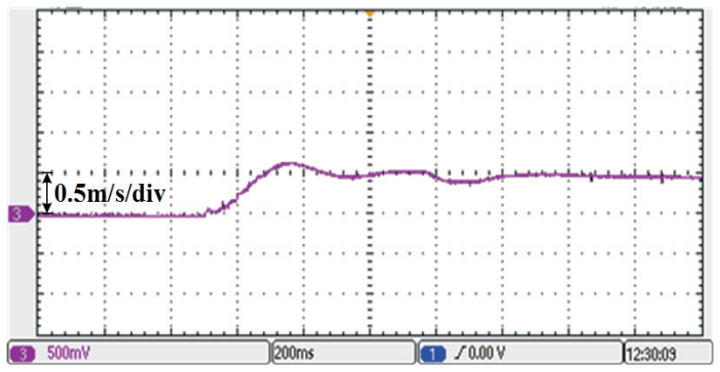

(a) PI control

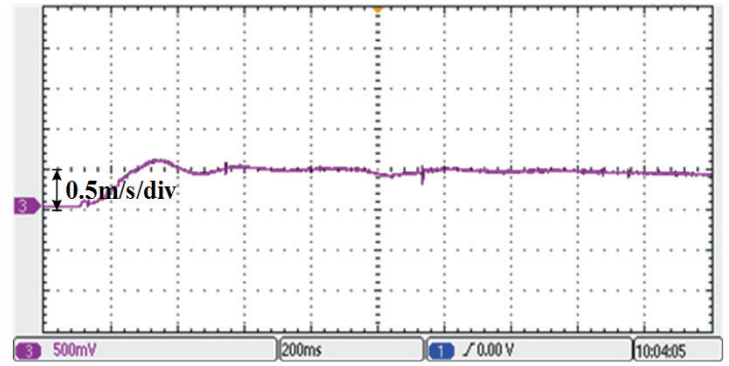

(b) ESO-based PFC control

Figure 7. Speed response curves.

\section{Conclusions}

The speed regulation problem for a PMLSM servo system has been investigated in this paper. The mathematical model of the PMLSM is established in the Laplace domain. A composite control scheme based on the PFC feedback and the ESO-based feedforward compensation has been presented. The simulation and experiment results confirm that the proposed composite control method has a superior system performance compared with the traditional PID control strategy, such as faster response speed and stronger robustness. Our future work will extend the proposed method to deal with the special force ripple and end effect problems in the PMLSM servo system. 
Author Contributions: This is a joint work and the authors were in charge of their expertise and capability: Y.W. (Yao Wang) for investigation and analysis; H.Y. for validation and revision; Z.C. for methodology and data analysis; Y.W. (Yuchen Wang) for writing and revision; C.Z. for manuscript revision.

Funding: This work was supported by the National Natural Science Foundationof China (NSFC) under Grant 41576096.

Acknowledgments: The authors would like to express their gratitude to all those who helped them during the writing of this paper. Also, the authors would like to thank the reviewers for their valuable comments and suggestions.

Conflicts of Interest: The authors declare no conflicts of interest.

\section{References}

1. Yang, C.Y.; Ma, T.T., Che, Z.Y.; Zhou, L.N. An adaptive-gain sliding mode observer for sensorless control of permanent magnet linear dynchronous motors. IEEE Access 2018, 6, 3469-3478. [CrossRef]

2. Wang, M.Y.; Yang, R.; Zhang, C.M.; Cao, J.W.; Li, L.Y. Inner loop design for PMLSM drives with thrust ripple compensation and high-performance current control. IEEE Trans. Ind. Electron. 2018, 65, 9905-9915. [CrossRef]

3. Song, F.Z.; Liu, Y.; Xu, J.X.; Yang, X.F.; Zhu, Q. Data-driven iterative feedforward tuning for a wafer stage: A high-order approach based on instrumental variables. IEEE Trans. Ind. Electron. 2019, 66, 3106-3116. [CrossRef]

4. Jang, K.B.; Kim, J.H.; An, H.J.; Kim, G.T. Optimal design of auxiliary teeth to minimize unbalanced phase due to end effect of PMLSM. IEEE Trans. Magn. 2011, 47, 1010-1013. [CrossRef]

5. Son, Y.I.; Kim, I.H.; Choi, D.S.; Shim, H. Robust cascade control of electric motor drives using dual reduced-order PI observer. IEEE Trans. Ind. Electron. 2015, 62, 3672-3682. [CrossRef]

6. Yang, C.Y.; Che, Z.Y.; Zhou, L.N. Integral sliding mode control for singularly perturbed systems with mismatched disturbances. Circuits Syst. Signal Process. 2019, 38, 1561-1582. [CrossRef]

7. Li, S.H.; Zong, K.; Liu, H.X. A composite speed controller based on a second-order model of permanent magnet synchronous motor system. Trans. Inst. Meas. Control 2011, 33, 522-541.

8. Huang, Y.; Xue, W.C. Active disturbance rejection control: Methodology and theoretical analysis. ISA Trans. 2014, 53, 963-976. [CrossRef]

9. Sira-Ramirez, H.; Linares-Flores, J.; Garcia-Rodriguez, C.; Contreras-Ordaz, M.A. On the control of the permanent magnet synchronous motor: An active disturbance rejection control approach. IEEE Trans. Control Syst. Technol. 2014, 22, 2056-2063. [CrossRef]

10. Yang, J.; Chen, W.H.; Li, S.H.; Guo, L.; Yan, Y.D. Disturbance/uncertainty estimation and attenuation techniques in PMSM drives-A survey. IEEE Trans. Ind. Electron. 2017, 64, 3273-3285. [CrossRef]

11. Ganesh, H.S.; Edgar, T.F.; Baldea, M. Model predictive control of the exit part temperature for an austenitization furnace. Processes 2016, 4, 53. [CrossRef]

12. Gong, Z.; Wu, X.J.; Dai, P.; Zhu, R.W. Modulated model predictive control for MMC-based active front-end rectifiers under unbalanced grid conditions. IEEE Trans. Ind. Electron. 2019, 66, 2398-2409. [CrossRef]

13. Yan, Y.D.; Zhang, C.L.; Narayan, A.; Yang, J.; Li, S.H.; Yu, H.Y. Generalized dynamic predictive control for nonparametric uncertain systems with application to series elastic actuators. IIEEE Trans. Ind. Inform. 2018, 14, 4829-4840. [CrossRef]

14. Yang, J.; Wu, H.; Hu, L.; Li, S.H. Robust predictive speed regulation of converter-driven DC motors via a discrete-time reduced-order GPIO. IEEE Trans. Ind. Electron. 2019, 66, 7893-7903. [CrossRef]

15. Vaccari, M.; Pannocchia, G. A modifier-adaptation strategy towards offset-free economic MPC. Processes 2017, 5, 2. [CrossRef]

16. Morel, F.; Lin-Shi, X.F.; Retif, J.M.; Allard, B.; Buttay, C. A comparative study of predictive current control schemes for a permanent-magnet synchronous machine drive. IEEE Trans. Ind. Electron. 2009, 56, 2715-2728. [CrossRef]

17. Bolognani, S.; Bolognani, S.; Peretti, L.; Zigliotto, M. Design and implementation of model predictive control for electrical motor drives. IEEE Trans. Ind. Electron. 2009, 56, 1925-1936. [CrossRef] 
18. Zhang, C.F.; Wu, G.P.; Rong, F.; Feng, J.H.; Jia, L.; He, J.; Huang, S.D. Robust fault-tolerant predictive current control for permanent magnet synchronous motors considering demagnetization fault. IEEE Trans. Ind. Electron. 2018, 65, 5324-5334. [CrossRef]

19. Liu, H.X.; Li, S.H. Speed control for PMSM servo system using predictive function control and extended state observer. IEEE Trans. Ind. Electron. 2012, 59, 1171-1183. [CrossRef]

20. Xue, W.C.; Bai, W.Y.; Yang, S.; Song, K.; Huang, Y.; Xie, H. ADRC with adaptive extended state observer and its application to air-fuel ratio control in gasoline engines. IEEE Trans. Ind. Electron. 2015, 62, 5847-5857. [CrossRef]

21. Wang, J.X.; Li, S.H.; Yang, J.; Wu, B.; Li, Q. Extended state observer-based sliding mode control for PWM-based DC-DC buck power converter systems with mismatched disturbances. IET Control Theory Appl. 2015, 9, 579-586. [CrossRef]

22. Chen, S.Y.; Chiang, H.H.; Liu, T.S.; Chang, C.H. Precision motion control of permanent magnet linear synchronous motors using adaptive fuzzy fractional-order sliding-mode control. IEEE/ASME Trans. Mechatron. 2019, 24, 741-752. [CrossRef]

23. Jin, H.Y.; Zhao, X.M. Complementary sliding mode control via elman neural network for permanent magnet linear servo system. IEEE Access 2019, 7, 82183-82193. [CrossRef]

24. Hu, J.G.; Liu, J.B.; Xu, L.Y. Eddy current effects on rotor position estimation and magnetic pole identification of PMSM at zero and low speeds. IEEE Trans. Power Electron. 2008, 23, 2565-2575. [CrossRef]

25. Yang, C.Y.; Liu, J.H.; Li, H.; Zhou, L.N. Energy modeling and parameter identification of dual-motor-driven belt conveyors without speed sensors. Energies 2018, 11, 3313. [CrossRef]

26. Yang, R.; Wang, M.Y.; Li, L.Y.; Zenggu, Y.M.; Jiang, J.L. Integrated uncertainty/disturbance compensation with second-order sliding-mode observer for PMLSM-driven motion stage. IEEE Trans. Power Electron. 2019, 34, 2597-2607. [CrossRef]

27. Lu, S.W.; Tang, X.Q.; Song, B.; Zheng, S.Q.; Zhou, F.X. Identification and compensation of force ripple in PMSLM using a JITL technique. Asian J. Control 2015, 17, 1559-1568. [CrossRef]

28. Mendez, J.A.; Kouvaritakis, B.; Rossiter, J.A. State-space approach to interpolation in MPC. Int. J. Robust Nonlinear Control 2000, 10, 27-38. [CrossRef]

29. Yang, C.Y.; Zhang, Q.L.; Sun, J.; Chai, T.Y. Lur'e Lyapunov function and absolute stability criterion for Lur'e singularly perturbed systems. IEEE Trans. Autom. Control 2011, 56, 2666-2671. [CrossRef]

30. Liu, M.; Zhang, L.X.; Shi, P.; Zhao, Y.X. Fault estimation sliding mode observer with digital communication constraints. IEEE Trans. Autom. Control 2018, 63, 3434-3441. [CrossRef]

31. Zhou, L.N.; Che, Z.Y.; Yang, C.Y. Disturbance observer-based integral sliding mode control for singularly perturbed systems with mismatched disturbances. IEEE Access 2018, 6, 9854-9861. [CrossRef] 